\title{
Refined glufosinate selection and its extent of exposure for improving the Agrobacterium-mediated transformation in Indian soybean (Glycine max) genotype JS-335
}

\author{
Alkesh Hada ${ }^{1,2}$, Veda Krishnan ${ }^{1,2}$, Mansi Punjabi ${ }^{1}$, Nabaneeta Basak', \\ Vanita Pandey', Theboral Jeevaraj², Ashish Marathe', Amit K Gupta', \\ Monica Jolly', Arun Kumar ${ }^{3}$, Anil Dahuja', Markandan Manickavasagam², \\ Andy Ganapathi ${ }^{2, *}$, Archana Sachdev ${ }^{1, *}$ \\ ${ }^{1}$ Division of Biochemistry, Indian Agricultural Research Institute, New Delhi 110 012, India; ${ }^{2}$ Department of Biotechnology \\ and Genetic Engineering, Bharathidasan University, Tiruchirappalli 620 024, India; ${ }^{3}$ National Phytotron Facility, Indian \\ Agricultural Research Institute, New Delhi 110 012, India \\ *E-mail: aganapathi2003@rediffmail.com Tel: +91-431-2407086 Fax:+91-431-2407045
}

Received July 12, 2015; accepted September 1, 2015 (Edited by T. Kobayashi)

\begin{abstract}
Soybean like many other crops, in this genomic era, has well-established genomic database which provides a wide range of opportunities for improvement through genetic manipulation. But the growing demand for soybean transgenics with increased production and improved quality has been handicapped due to inefficient transformation strategies and hence an efficient, stable and reliable transformation system is of prime requisite. In the present study, Agrobacterium-mediated transformation was standardized by refining the glufosinate selection system in terms of dosage $\left(0-6 \mathrm{mgl}^{-1}\right)$ and degree of exposure. The cotyledonary node explants (with and without wounding) initially cultured on a non-selective shoot induction medium for 10 days before transferring them to the selective SIM with an optimized concentration of $5.0 \mathrm{mgl}^{-1}$ ammonium glufosinate, showed least selection escape frequency. Wounded cotyledonary node explants infected with Agrobacterium tumefaciens harboring pBIN-bar construct, showed an improved regeneration efficiency of $55.10 \%$ and transformation efficiency of $12.6 \%$ using Southern blotting in $\mathrm{T}_{1}$ plants. Southern analysis of $\mathrm{T}_{1}$ plants confirmed the integration of bar gene into the genomic DNA and the bar positive $\mathrm{T}_{1}$ plants segregated in 3:1 ratio. This is the first report, to our knowledge, of a high transformation efficiency using Agrobacterium-mediated cot nodeglufosinate system in an Indian soybean genotype.
\end{abstract}

Key words: Agrobacterium tumefaciens, ammonium glufosinate, cotyledonary-node, soybean, transformation.

Soybean is one of the most potential sources of vegetable oil, protein and nutraceuticals in the world and researchers have long sought to modify and optimize its functional characteristics (Trick et al. 1997). More precisely, advancement in genetic engineering and transgenic technologies have been of immense help in alleviating the existing restrictions in the traditional soybean breeding due to the limited availability of germ plasm to generate enough allelic diversity. Progress, however, in both genetic improvement and functional genomics research is still constrained due to the lack of efficient transformation systems which are not able to meet the demands of the current high through put analysis in soybean functional genomics. The two methods of transformation used routinely over the past two decades with relatively greater success have been biolistic-mediated transformation of soybean embryogenic cultures (Finer and Mc Mullen 1991, 1992; Hadi et al. 1996; Hazel et al. 1998; Parrott et al. 1994; Santarem and Finer 1999; Stewart et al. 1996) and the Agrobacterium-mediated transformation of cotyledonary node $(\mathrm{CN})$ through direct organogenesis (Clemente et al. 2000; Di et al. 1996; Hinchee et al. 1988; Zhang et al. 1999).

But the reported transformation efficiencies are still low by these methods and like in other recalcitrant crops, the protocols are often genotype or tissue specific making a routine recovery of stable transformants still restricted (Somers et al. 2003; Widholm 1995). Also, many reports have not yet been explored on Indian genotypes of

Abbreviations: CN, Cotyledonary node; PPT, Phosphinothricin; GM, Germination medium; CCM-L, Co-cultivation medium (Liquid); CCM-S, -Co-cultivation medium (Solid); SIM, Shoot induction medium; SEM, Shoot elongation medium; RM, Rooting medium; MIC, Minimum inhibitory concentration; BAP, 6-Benzylaminopurine; IBA, Indole-3-butyric acid; $\mathrm{GA}_{3}$, Gibberellic acid; DTT, Dithiothreitol.

This article can be found at http://www.jspcmb.jp/

Published online December 17, 2016 
soybean.

Bio fortification of soybean genotypes, using metabolic engineering approaches like RNAi, activation tags, enhancer traps etc., being the forthcoming mandate for developing countries like India, whereas its success solely depends on a rapid and efficient transformation protocol specially for the popular, high yielding Indian soybean cultivars. An attempt has thus been made in the present study to standardize a transformation protocol for the Indian soybean genotype JS-335 by optimizing the selection system.

To accomplish the task of generating efficient transgenics, selective agents and marker genes play a pivotal role providing a selective advantage to the transformed cells by allowing them a better and faster growth. Incomplete selection of transformed cells is evidenced by the development of non-transformed plants/escapes and hence an optimum dosage of selection agents is vital to distinguish transformed cells from the untransformed ones (Hinchee et al. 1988). Due to better efficiency, availability and applicability, antibiotics like kanamycin, hygromycin and herbicides like glufosinate are still being widely used for selection (Sundar et al. 2008). It has however been reported that glufosinate is a better choice for an efficient selection in case of soybean (Wang et al. 2003). Zhang et al. (1999) used glufosinate for the selection of transformed soybean cultivar Asgrow 3237 with an efficiency of about $3 \%$ and later glufosinate has also been widely used in the efficient, rapid recovery of transgenics due to its rapid translocation into soybean tissues through xylem and phloem (Shelp et al. 1992). These selection systems have also been credited due to its effective selection over other agents such as hygromycin $\mathrm{B}$ and kanamycin resulting in low frequency of selection escapes (Zeng et al. 2004).

The effectiveness of a selection regime of transformants also depends on an optimum dosage, the time of application as well as an effective exposure of the explants to the selection agent (Bowen 1993). The CN system involves wounding of explants derived from 5-7 days old seedling by making accurate incisions on the adaxial side for providing entry for agro infection. Other soybean transformation approaches involving some forms of deliberate wounding on explants, like sonication assisted Agrobacterium-mediated transformation (SAAT) and vacuum infiltration, have also been explored, resulting in different transformation efficiencies. In this study, we provide an additional wounding; a precise incision done on the explants before transferring them to the shoot induction medium (SIM) to have further direct contact with the selection agent, hypothesizing a positive effect due to increased exposure.

Hence forth, with an aim to develop an effective tissue culture selection regime for Agrobacterium-mediated CN method of soybean transformation in JS-335, we first evaluated and determined an optimum concentration of the herbicide (ammonium glufosinate), for an efficient selection of transformants with least selection escape frequency followed by determining the effect of exposing the explants directly through additional wounding in SIM containing selection agent for reducing the selection escapes. Significant increase in the transformation efficiency was confirmed by molecular analysis. We here by provide to the best of our knowledge, the first report of the Agrobacterium-mediated transformation using CN in Indian cultivar JS-335.

\section{Materials and methods}

\section{Plant material}

Soybean cv. JS-335 was used for the standardization of the Agrobacterium-mediated genetic transformation and the seeds were procured from Directorate of Soybean Research (DOSR), Indore, Madhya Pradesh, India. Chlorination of the seeds for $16 \mathrm{~h}$ was done in a tightly sealed desiccator (Tarsons, India) containing chlorine gas produced by mixing $3.5 \mathrm{ml}$ of $12 \mathrm{~N} \mathrm{HCl}$ and $100 \mathrm{ml}$ of $5.25 \%$ sodium hypochlorite (Di et al. 1996). The hilum of the surface-sterilized seeds was inserted proximally in the B5 medium (Gamborg et al. 1968) ( $\mathrm{pH}$ 5.8) solidified with $0.6 \%$ PTC agar (w/v) (HIMEDIA, India) and incubated for 5-6 days under cool white fluorescent lamps (Philips, New Delhi, India) at an intensity of $50 \mu \mathrm{mol} \mathrm{m} \mathrm{m}^{-2} \mathrm{~s}^{-1}$ for a 16 -h photoperiod until the seed coats split open (Olhoft et al. 2003).

\section{Agrobacterium culture preparation}

The A. tumefaciens strain EHA 105 harboring the binary construct pBIN-bar was used for the transformation experiments. The binary construct pBIN-bar containing the bar gene within the T-DNA borders, was introduced into the super virulent A. tumefaciens, EHA 105 via triparental

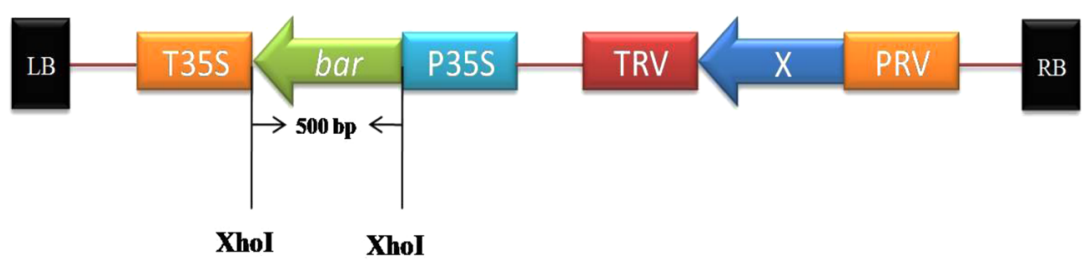

Figure 1. T-DNA region of the binary vector pBIN-bar. LB, left border; RB, right boarder; T35S, terminator; bar, phosphinothricin acetyl transferase gene; P35S, CaMV 35S promoter; TRV, vicillin terminator; X, gene (data not shown); PRV, vicillin promoter. 
mating (Figure 1). EHA 105 stocks were revived and streaked on solidified Luria agar (LA) (casein enzymatic hydrolysate $10 \mathrm{gl}^{-1}$, yeast extract $5 \mathrm{gl}^{-1}$, sodium chloride $5 \mathrm{gl}^{-1}$ and agar $\left.15 \mathrm{gl}^{-1}\right)$ containing kanamycin salt $\left(50 \mathrm{mgl}^{-1}\right)$ and rifampicin $\left(30 \mathrm{mgl}^{-1}\right)$ and incubated at $28^{\circ} \mathrm{C}$ for $48 \mathrm{~h}$ until colony formation.

The colonies were inoculated in $5 \mathrm{ml}$ Luria broth (LB) supplemented with rifampicin $\left(30 \mathrm{mgl}^{-1}\right)$ and kanamycin $\left(50 \mathrm{mgl}^{-1}\right)$ and incubated at $28^{\circ} \mathrm{C} / 200 \mathrm{rpm}$ for overnight. The overnight grown cultures were re-inoculated into $50 \mathrm{ml} \mathrm{LB}$ broth medium with antibiotics and incubated at $28^{\circ} \mathrm{C} / 200$ rpm until the $\mathrm{OD}_{600}$ reaches $0.8-1.0$. The bacterial culture was centrifuged for $10 \mathrm{~min}$ at $4^{\circ} \mathrm{C} / 4000 \mathrm{rpm}$ to pellet the cells. The bacterial pellet was subsequently washed in $5 \mathrm{ml}$ liquid co-cultivation [CCM-L: B5 salts 1/10X, B5 Iron 1/10X, B5 Vitamins 1/10X, Sucrose (w/v) 0.3\%, BAP $1.67 \mathrm{mgl}^{-1}$, Acetosyringone $0.2 \mathrm{mM}$, L-cysteine $3.3 \mathrm{mM}$, Sodiumthiosulphate $1 \mathrm{mM}$, DTT $1 \mathrm{mM}$ ( $\mathrm{pH}$ 5.4)]. The suspended culture was re-centrifuged at $4^{\circ} \mathrm{C} / 4000 \mathrm{rpm}$ for $10 \mathrm{~min}$. A. tumefaciens pellet was finally suspended in CCM-L to obtain a suitable $\mathrm{OD}_{600}$ of 0.5 .

\section{Experimental design and analysis}

To ascertain the optimum concentration of ammonium glufosinate, an initial experiment was designed in which, the co-cultivated explants were pre-cultured on non-selective SIM for 10 days before transferring them to SIM supplemented with different concentrations of glufosinate $(0,1,2,3,4,5$ and $6 \mathrm{mgl}^{-1}$ ) for the selection of true transformants. 100 explants were analyzed for each concentration.

In the second experiment, co-cultivated explants were placed in the non-selective SIM for 10 days following which the newly developed calli were cut precisely (additional wounding), and then transferred to SIM supplemented with seven different concentrations of glufosinate $\left(0-6 \mathrm{mgl}^{-1}\right)$ hypothesizing that the extended exposure to the selection agent might reduce further selection escapes.

The experimental materials from the above two experiments were transferred to SEM and the data were recorded after 24 days based on regeneration. Independent transformation events arising from single explant were tracked and the survival percentage was hence calculated as,

$\%$ Survival $=$

[Number of independent survived plants/ total number of explants inoculated $\times 100]$.

\section{Genetic transformation procedure}

The CN method described in the present study was modified from Olhoft et al. (2001). Sterilized germinated seedlings were used as an explant source and from a single seedling; two explants were obtained by removing the roots and majority of the hypocotyl (approx. 3-5 cm).

A vertical cut was made through the remaining hypocotyl with a sterile surgical blade No. 24 (Paramount Surgimed Ltd., India) with high precision. The epicotyls were subsequently removed and both the cot-node and the axilliary bud were wounded 5-10 times each with tip of the blade. Explants were then incubated with $50 \mathrm{ml}$ co-cultivation/Agrobacterium suspension for $45 \mathrm{~min}$ to $1 \mathrm{~h}$ and 5-10 explants were then placed in each petriplate $(90 \mathrm{~mm}$ diameter $\times 15 \mathrm{~mm}$ deep $)$ with the adaxial side down on a sterile $90 \mathrm{~mm}$ Whatman $\neq 1$ filter paper (Whatman International, UK) placed on solid cocultivation medium [CCM-S: B5 salts 1/10X, B5 Iron 1/10X, B5 Vitamins 1/10X, Sucrose (w/v) 0.3\%, BAP $1.67 \mathrm{mgl}^{-1}$, Acetosyringone $0.2 \mathrm{mM}$, L-cysteine $3.3 \mathrm{mM}$, Sodiumthiosulphate $1 \mathrm{mM}$, DTT $1 \mathrm{mM}$, PTC $\operatorname{agar}(\mathrm{w} / \mathrm{v}) 0.6 \%(\mathrm{pH}$ 5.4)]. The petriplates were stacked and sealed with parafilm ' $M$ ' (BEMIS, USA) and incubated at $25 \pm 2^{\circ} \mathrm{C}$ for 3 days in the dark.

\section{Plant regeneration and selection}

The co-cultivated explants were thoroughly washed in liquid shoot induction medium [SIM-L: B5 salts 1X, B5 Iron 1X, B5 Vitamins 1X, Sucrose (w/v) 3\%, BAP $1.2 \mathrm{mgl}^{-1}$, IBA $0.2 \mathrm{mgl}^{-1}$, Cefotaxime $200 \mathrm{mgl}^{-1}$, Carbenicillin $100 \mathrm{mgl}^{-1}$, Augmentin $70 \mathrm{mgl}^{-1}$ (pH 5.8)] and dried on a sterile $90 \mathrm{~mm}$ Whatman $\neq 1$ filter paper (Whatman International, UK) to remove the excess A. tumefaciens. The explants were then placed on solid Shoot Induction Medium [SIM-S: B5 salts 1X, B5 Iron 1X, B5 Vitamins 1X, Sucrose (w/v) 3\%, BAP $1.2 \mathrm{mgl}^{-1}$, IBA $0.2 \mathrm{mgl}^{-1}$, PTC agar (w/v) 0.7\% Cefotaxime $200 \mathrm{mgl}^{-1}$, Carbenicillin $100 \mathrm{mgl}^{-1}$, Augmentin $70 \mathrm{mgl}^{-1}$ (pH 5.8)] without the selection pressure for 10 days. After induction, the explants were wounded and transferred to SIM-II containing $5 \mathrm{mgl}^{-1}$ glufosinate. After 12 days the explants from the SIM were transferred onto the Shoot Elongation Medium [SEM: MS salts 1X, MS Iron 1X, MS Vitamins $1 \mathrm{X}$, Sucrose (w/v) 3\%, GA $0.75 \mathrm{mgl}^{-1}$, PTC agar (w/v) $0.7 \%$ (pH 5.8)] containing filter sterilized glufosinate $\left(5 \mathrm{mgl}^{-1}\right)$. Explants were sub-cultured at regular intervals of 12 days onto fresh SEM until they reached a height of $4-5 \mathrm{~cm}$. Those which survived the selection were further transferred onto the rooting medium [RM: MS salts 1/2X, MS Iron 1/2X, MS Vitamins 1/2X, Sucrose (w/v) 2\%, IBA $2.0 \mathrm{mgl}^{-1}$, PTC agar (w/v) 0.6\% (pH 5.8)]. After 14-20 days, the rooted transformants were hardened into pot mix (Vermiculite, Cocopeat and Sand, 1:1:1). $\mathrm{T}_{0}$ plants were shifted to National Phytotron Facility, Indian Agricultural Research Institute, New Delhi, for acclimatization and maturation. Leaf samples were collected for molecular analysis of the putative transformants after 30 days and $\mathrm{T}_{1}$ seeds were selfed and sown further for determining the segregation pattern.

\section{Genomic DNA extraction and PCR analysis}

To confirm the transgene integration, PCR analysis of $\mathrm{T}_{0}, \mathrm{~T}_{1}$ and $\mathrm{T}_{2}$ events were performed with bar gene specific primers. Total genomic DNA was isolated from transformed and nontransformed control plant leaf tissue samples using the CTAB method (Doyle and Doyle 1987). The PCR mixture contained $1 \mu \mathrm{g}$ of genomic DNA, each primer at a concentration of $10 \mathrm{mM}$ in Tris- $\mathrm{HCl}(\mathrm{pH} 8.8), 50 \mathrm{mM} \mathrm{KCl}, 1.5 \mathrm{mMMgCl}_{2}$, $1 \%$ Triton X100, $0.1 \mathrm{mM}$ dNTPs and 1 unit of Taq DNA 
polymerase (Fermentas, USA) in a total volume of $50 \mu$ l. The PCR reaction was carried out in an automated thermal cycler (Biorad, USA) programmed with an initial denaturation of DNA at $94^{\circ} \mathrm{C}$ for $2 \mathrm{~min}$, followed by 35 cycles of $94^{\circ} \mathrm{C}$ for $30 \mathrm{~s}$, $64^{\circ} \mathrm{C}$ for $1 \mathrm{~min}, 72^{\circ} \mathrm{C}$ for $1 \mathrm{~min}$, followed by final extension at $72^{\circ} \mathrm{C}$ for $10 \mathrm{~min}$. The bar specific primers used were bar FP: 5'GAA CGA CGC CCG GCC GAC AT 3'; bar RP: 5' GTCCAGCTGCCA GAA ACCCAC 3'. Plasmid pBINbar served as a positive control and the non-transformed tissue culture generated plant was used as a template for the negative control. The amplified products were analyzed by electrophoresis on a $1.0 \%(\mathrm{w} / \mathrm{v})$ agarose gel. One kb ladder which served as a molecular weight marker was obtained from Fermentas, USA.

\section{Southern blot analysis}

Southern blot hybridization was performed to verify the integration of bar gene in the soybean genome. About $10 \mu \mathrm{g}$ of the genomic DNA isolated from the $\mathrm{T}_{0}$ and $\mathrm{T}_{1}$ transformants were used for Southern analysis which was performed according to Sambrook et al. (1989). Total genomic DNA was digested with $X h o I$ restriction enzyme in a reaction volume of $50 \mu \mathrm{l}$ and incubated at $37^{\circ} \mathrm{C}$ for $16-18 \mathrm{~h}$. XhoI having a unique site in the binary construct (pBIN-bar) was expected to release the fragment of $500 \mathrm{bp}$. The restricted DNA was electrophoresed and separated on $0.8 \%(\mathrm{w} / \mathrm{v})$ agarose gel and blotted onto the nitrocellulose membrane (MDI, India). The membranes were pre-hybridized in $10 \mathrm{ml}$ of pre-hybridization solution (Supplementary Table 1 ) at $65^{\circ} \mathrm{C}$ for $3-4 \mathrm{~h}$. The bar gene released by PCR was purified through PCR purification kit (Invitrogen, USA) and labeled using random primers provided in the labeling kit (Banglore Genei, India). About $10 \mu \mathrm{l}$ of $\alpha^{32} \mathrm{P}$ dCTP labelled $500 \mathrm{bp}$ bar probe $\left(0.5 \times 106 \mathrm{dpm} \mu \mathrm{l}^{-1}\right)$ was added to $10 \mathrm{ml}$ of pre-hybridization solution and kept at $65^{\circ} \mathrm{C}$ in the hybridization oven for over-night. The membranes were washed thrice with $2 \mathrm{X}$ SSC, $0.1 \%$ SDS, for duration of $15 \mathrm{~min}$ each. The image was captured in a phosphor-imager (PerkinElmer, Inc., USA) and transferred further on an X-ray film (Kodak, India). Transformation efficiency was calculated based on $\mathrm{T}_{1}$ results.

\section{Segregation analysis of transgene}

The segregation pattern of the transgene (bar) in $\mathrm{T}_{1}$ generation was confirmed on the basis of the PCR analysis (transgene positive: transgene negative) conducted in $\mathrm{T}_{1}$ lines. A chi-square analysis test was conducted to determine the segregation ratios, where significance was determined for those values with a $p$ value less than 0.05 .

\section{Agronomic performance of transgenic plants}

For the evaluation of the agronomic performance of transgenic (T), tissue cultured generated non-transgenic (NT) and wild type plants (WT), different parameters like plant height $(\mathrm{cm})$, number of pods, number of seeds, seed dry weight $(\mathrm{mg})$ and root length $(\mathrm{cm})$ were observed. From each of the Southern positive transgenics lines, 10 plants were picked and evaluated for studying each parameter.

\section{Statistical Analysis}

The experimental design was randomized, 100 explants were analyzed for each of the concentration of glufosinate used for optimization, keeping all other parameters except glufosinate concentrations constant. Each explant was considered as an experimental unit and was tracked individually. The survival as well as transformation efficiency data was expressed as absolute (in percentage) at $p<0.05$. Wounding experiments followed by pBIN-bar transformation were also similarly performed. The mean values of treatments were subjected to Duncan Multiple Range Test (DMRT). The segregation analysis of $\mathrm{T}_{1}$ generation was conducted by chi-square analysis, where $p$-value less than 0.05 was considered as statistically significant and was calculated using MSTAT-C programme.

\section{Results and discussion}

Effect of glufosinate concentration and wounding in optimizing selection regime to minimize escape frequency

The modified $\mathrm{CN}$ method used in the present experiment is illustrated in Figure 2. The base vector pBIN-bar containing a bar gene was used in the present study (Figure 1) where bar gene encodes for the enzyme, phosphoinothricin acetyl transferase (PAT), which acetylates the free amino group of glufosinate rendering it inactive and incapable of binding to glutamine synthetase (Thompson et al. 1987; Wehrmann et al. 1996). Glutamine synthetase is required for the production of glutamine and prevents ammonia accumulation in the cell. The bar-glufosinate system has been used as an effective selection agent in plant transformations in various crops (Dennehey et al. 1994; Wang et al. 2003) as well as in soybean (Zhang et al. 1999), though the efficacy of selection has shown considerable variations. To evaluate the stringency, killer curve experiments were performed to determine the dose response of soybean $\mathrm{CN}$ explants to selective SIM containing glufosinate after co-cultivation. Exhibition of severe tissue necrosis and failure to develop shoots revealed the stringency and lethality associated with the selection agent (data not shown). Therefore, in the present study, the explants were precultured for 10 days in the non-selective SIM and then transferred into selective SIM having different concentrations of glufosinate $\left(0-6 \mathrm{mgl}^{-1}\right)$. The delay in application of selection pressure for 10 days stimulated the regeneration of the shoots. The study revealed that the explants were able to survive up to $5 \mathrm{mgl}^{-1}$ of glufosinate concentration and produced viable shoots and roots from the transformed tissue. The maximum selection efficacy of glufosinate was thus observed at $5 \mathrm{mgl}^{-1}$ with $90 \%$ inhibition in the escapes and the 

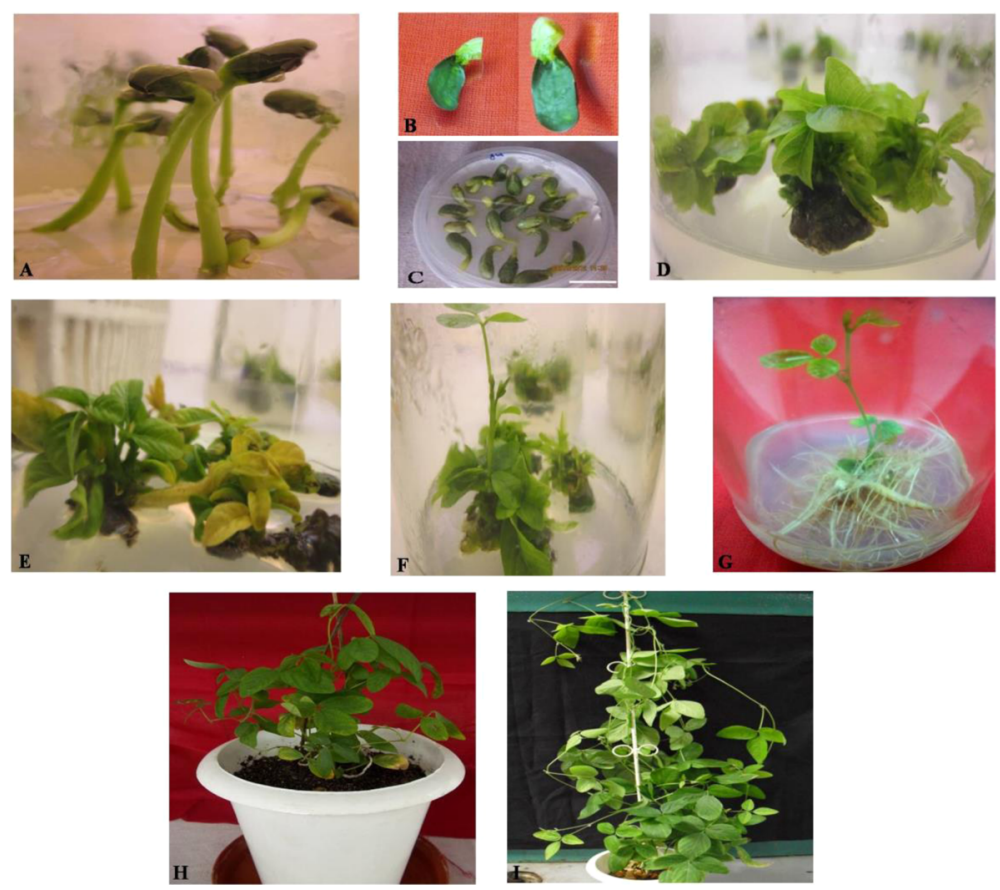

Figure 2. A modified CN method using glufosinate as the selection agent. Explants were prepared from six days-old seedlings of JS-335 by removing the majority of the hypocotyl from the cotyledons and wounding the axillary meristematic tissue at the cotyledonary-node. (A) Seedling grown in GM for explants preparation (B) Cotyledons were separated and prepared for Agrobacterium infection. (C) Explants were inoculated with Agrobacterium tumefaciens and co-cultivated (D) CN were embedded onto antibiotic free SIM-I to stimulate de novo shoot formation from the wounded axillary meristematic tissue (E) Explants were transferred to SIM-II containing $5 \mathrm{mgl}^{-1}$ glufosinate for 12 days (F) Explants were cultured for 14 days on SEM containing $5 \mathrm{mgl}^{-1}$ glufosinate $(\mathrm{G})$ Elongated shoots were placed onto RM for root development (H) Plantlets were hardened in sterilized pot mix in the tissue culture facility (I) Growing plantlets were shifted to greenhouse, plants acclimatized and reached maturity.

regeneration and development occurred only from the transformed tissues (Figure 3a). Earlier, Zhang et al. (1999) achieved transformation efficiency in the range of $0-3 \%$ producing a putative primary transformants with Asgrow 3237 using $3.3 \mathrm{mgl}^{-1}$ glufosinate. Concentrations as high as $10 \mathrm{mgl}^{-1}$, were also employed by Tran Thi Cuc Hoa (2008) in different soybean varieties. The varied glufosinate concentration observed revealed the role of Minimum Inhibitory Concentration (MIC) requirement for a given cultivar for inducing growth and differentiation from the transformed tissue. Zhang et al. (1999) however reported that the regeneration of shoots was suppressed at higher concentrations like $10 \mathrm{mgl}^{-1}$ in soybean.

Physical contact between the explant and the medium improves the uptake or transport of glufosinate into plant cells and thus might improves its efficacy (Anne and Elizabeth 1996). Keeping this in mind, we tried to analyze the combined effect of wounding and glufosinate concentration in improving the regeneration efficiency. The tolerance level of glufosinate was tested by placing explants in a non-selective SIM for 10 days before transferring them to a selective SIM soon after precisely wounding the half $\mathrm{CN}$ and a part of the callus. It was found that the survival rate of the non-transformed tissue further decreased. At $5 \mathrm{mgl}^{-1}$ concentration, $96 \%$ inhibition of regeneration was observed, which clearly depicted the role of precise wounding in evoking stringent selection response in the non-transformed tissue (Figure $3 \mathrm{~b}$ ). We found $5 \mathrm{mgl}^{-1}$ as the best inhibitory concentration of glufosinate to be used for selecting transformed plants as on increasing it to $6 \mathrm{mgl}^{-1}$ only a few calli regenerated and most observed were with severe yellowing and necrosis and hence not viable. The increased rates of uptake or transport of glufosinate by plant tissues and cells during selection might have significantly reduced the escape frequency (Dennehey et al. 1994). According to Hansen and Wright (1999) to obtain a successful transformation process, it is necessary to have competent target tissues to be regenerated, agents that select transgenic tissues and process that should be simple and cost effective. The present study keeping the above in view offers reliable selection regime resulting in both higher transformation efficiency and regeneration frequency. The results are very much in line with the previous studies conducted using the very same selection agent at varied concentrations in genus Medicago (D’Hallunm et al. 1990), Pisum (Schroeder et al. 1993), Arabidopsis (Akama et al. 1995), Carica (CabreraPonce et al. 1995), Nymphea (Pigeaire et al. 1997), Glycine (Zhang et al. 1999), Daucus (Chen et al. 2002), Saccharum (Manickavasagam et al. 2004) and Cucumis (Vasudevan et al. 2007). The use of $\mathrm{CN}$ has an advantage of yielding higher rate of regeneration with multiple 
shoots while optimal wounding and genotype attributes also result in multi shoot phenotype. In the present study, JS-335 produced 2-3 shoots per CN and neither the effect of glufosinate concentration nor wounding observed in the shoot development.

\section{Effect of wounding and optimum glufosinate concentration on regeneration frequency}

A total of 490 wounded soybean explants were

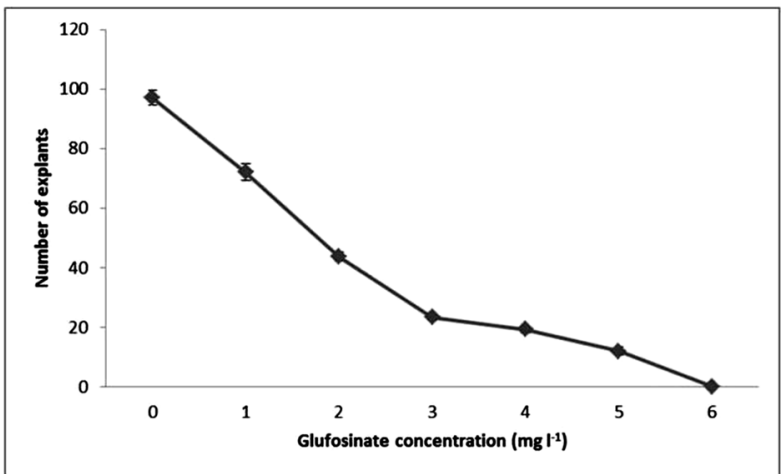

(a)

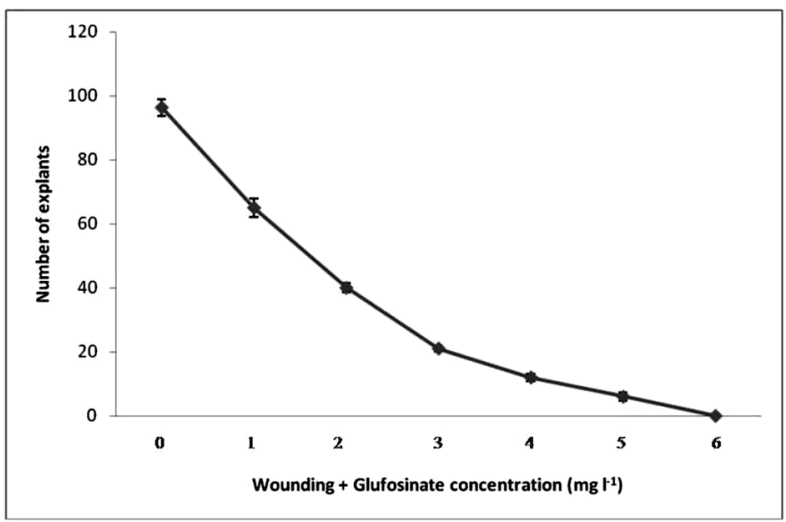

(b)

Figure 3. Killer response curve. (a) Based on the survival rate of soybean explants in selective SIM with different concentrations of glufosinate. (b) Based on the survival rate of soybean explants in selective SIM with different concentrations of glufosinate after wounding. transferred to the selective SIM-II containing $5 \mathrm{mgl}^{-1}$ glufosinate after 10 days. At this point, significant portion of the non-transformed calli had senesced. $74.48 \%$ of the explants survived in selective SIM-II containing optimum glufosinate selection pressure and the pressure was adequate for rapid cell death without jeopardizing the survival of the transformed tissue. 365 of the regenerated explants were transferred to SEM containing $5 \mathrm{mgl}^{-1}$ glufosinate and a $55.10 \%$ regeneration frequency was observed (Table 1). Kuta and Tripathi (2005) reported various other parameters such as type of explants, age of explants, pre-culture period, density of bacterial inoculums, infection duration, and media compositions to affect the regeneration frequency. Higher regeneration frequency was reported using embryonic tips (87.7\%) as compared with CN (40\%) and hypocotyl segments (50\%) (Liu et al. 2004). Improved regeneration frequency thus achieved in the present study was a result of optimizing the concentration and exposure to the selection medium. The transformed elongated plants were further transferred to the rooting medium after 24 days and were subsequently hardened.

\section{Molecular analysis and phenotyping of transformed soybean plants}

Independent transformation events and subsequent generations were confirmed based on their resistance to the herbicide, giving an overall efficiency of $14.4 \%$ using PCR and $12.6 \%$ (Southern blotting) (Table 2). The improved efficiency observed might be due to optimum glufosinate concentration along with wounding which improved the extent of exposure of the explants to the selection agent. Although the transformation efficiency reported in our study is not an improvement over the $16.4 \%$ efficiency reported by Olhoft et al. (2003), but our study is the first report, to our knowledge, revealing the highest efficiency of $12.6 \%$ using $\mathrm{CN}$-glufosinate system in an Indian cultivar. For the Southern analysis, $\mathrm{PCR}^{+\mathrm{ve}} \mathrm{T}_{0}$ plants and $\mathrm{T}_{1}$ plants were selected and their leaf tissues were collected for DNA extraction. Total genomic DNA were digested with XhoI and the Southern blots were hybridized with the bar probe $\left(\alpha^{32} \mathrm{P}\right.$-labeled).

Table 1. Effect of wounding and optimum glufosinate concentration on regeneration efficiency.

\begin{tabular}{cccc}
\hline Experiment number & $\begin{array}{c}\text { Number of explants Infected } \\
\text { in SIM }\end{array}$ & $\begin{array}{c}\text { Mean No. of regeneration efficiency } \\
\text { \% of regeneration efficiency in SEM }^{\text {a }}\end{array}$ \\
\hline 1 & 85 & $59 \pm 0.006^{\mathrm{d}}$ & $47 \pm 0.004^{\mathrm{b}}$ \\
2 & 75 & $54 \pm 0.005^{\mathrm{f}}$ & $41 \pm 0.006^{\mathrm{e}}$ \\
4 & 83 & $61 \pm 0.006^{\mathrm{b}}$ & $44 \pm 0.004^{\mathrm{d}}$ \\
5 & 78 & $60 \pm 0.004^{\mathrm{bc}}$ & $45 \pm 0.006^{\mathrm{c}}$ \\
& 95 & $73 \pm 0.006^{\mathrm{a}}$ & $49 \pm 0.005^{\mathrm{a}}$ \\
& 74 & $58 \pm 0.005^{\mathrm{e}}$ & $44 \pm 0.005^{\mathrm{de}}$ \\
\hline
\end{tabular}

a $\%$ of regeneration efficiency calculated on the basis of the survived explants under glufosinate $5 \mathrm{mgl}^{-1}$ selection pressure. $*$ Regeneration efficiency $=$ No. of explants grown in selection pressure/total number of explants infected $\times 100$. Mean values of three independent experiments $( \pm)$ with standard error. Values with the same letter within columns are not significantly different according to Duncan's Multiple Range Test (DMRT) at a 5\% level. 
Table 2. Transformation efficiency of in soybean cot-node subjected to glufosinate selection.

\begin{tabular}{ccccc}
\hline Experiment number & No. of explants infected & $\begin{array}{c}\text { Mean No. of glufosinate } \\
\text { resistant events in } \mathrm{T}_{0} \\
\text { generation }\left(\text { bar }^{+\mathrm{ve}}\right)\end{array}$ & $\begin{array}{c}\text { Transformation efficiency by } \\
\text { PCR }^{\mathrm{a}}(\%)\end{array}$ & $\begin{array}{c}\text { Final transformation } \\
\text { efficiency by Southern } \\
\text { blotting }^{\mathrm{b}}(\%)\end{array}$ \\
\hline 1 & 85 & $11 \pm 0.006^{\mathrm{d}}$ & $12.9 \pm 0.004^{\mathrm{e}}$ & $12.9 \pm 0.006^{\mathrm{c}}$ \\
2 & 75 & $10 \pm 0.006^{\mathrm{f}}$ & $13.3 \pm 0.006^{\mathrm{c}}$ & $12.0 \pm 0.005^{\mathrm{d}}$ \\
4 & 83 & $11 \pm 0.004^{\mathrm{de}}$ & $13.2 \pm 0.006^{\mathrm{cd}}$ & $10.8 \pm 0.006^{\mathrm{e}}$ \\
5 & 78 & $13 \pm 0.006^{\mathrm{b}}$ & $16.6 \pm 0.005^{\mathrm{b}}$ & $14.1 \pm 0.005^{\mathrm{b}}$ \\
& 95 & $12 \pm 0.005^{\mathrm{c}}$ & $12.6 \pm 0.006^{\mathrm{f}}$ & $10.5 \pm 0.004^{\mathrm{ef}}$ \\
& 74 & $14 \pm 0.006^{\mathrm{a}}$ & $18.9 \pm 0.005^{\mathrm{a}}$ & $16.2 \pm 0.004^{\mathrm{a}}$ \\
& & Mean transformation & $\mathbf{1 4 . 4 \pm 0 . 0 0 5}$ & $\mathbf{1 2 . 6 \pm 0 . 0 0 4}$
\end{tabular}

a Transformation efficiency $=\left(\right.$ No. of $\mathrm{PCR}^{+\mathrm{ve}} \mathrm{T}_{0}$ events/No. of explants infected $) \times 100{ }^{\mathrm{b}}$ Final transformation efficiency $=\left(\right.$ No. of Southern blot ${ }^{+v e} \mathrm{~T}_{1}$ events/No. of explants infected) $\times 100$. Mean values of three independent experiments $( \pm)$ with standard error. Values with the same letter within columns are not significantly different according to Duncan's Multiple Range Test (DMRT) at a 5\% level.

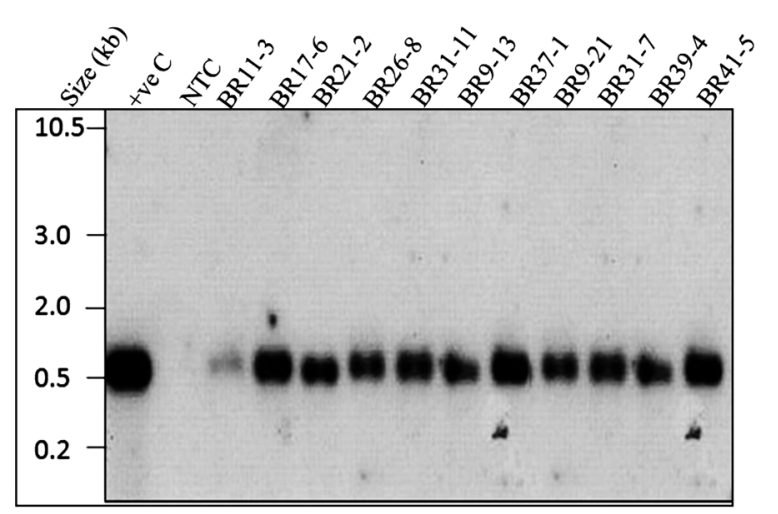

(a)

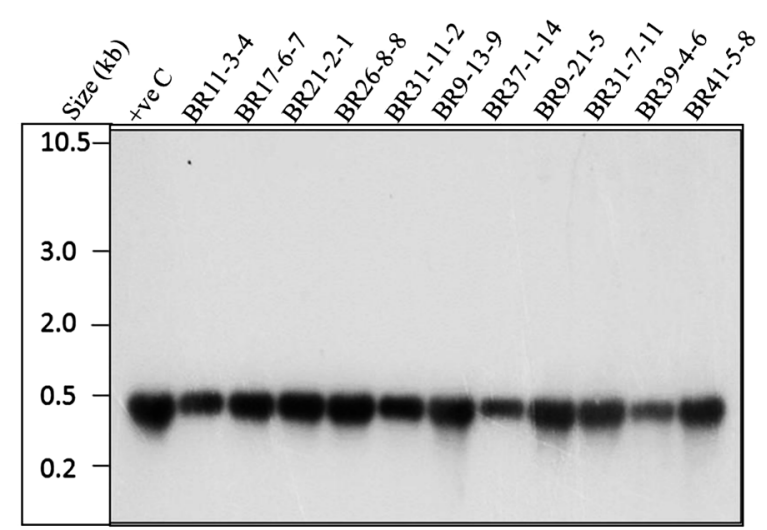

(b)

Figure 4. Southern blot hybridization analysis of total genomic DNA from (a) $\mathrm{T}_{0}$ plants (b) $\mathrm{T}_{1}$ plants. DNA was extracted from transformed plants, digested with $\mathrm{XhoI}$, and hybridized with $\alpha^{32} \mathrm{P}$-labeled bar probes to produce unique fragments for each integrated T-DNA representing the transgene (bar). lane + ve C, shows the positive control (restricted pBIN-bar with XhoI); lane NTC, shows negative control (nontransformed plant); lane BR11-3 to BR41-5 and lane BR11-3-4 to BR415-8, shows independent transgenic lines.

Transgenes were detected in all the herbicide resistant $\mathrm{T}_{0}$ plants as exemplified in Figure 4a. Because XhoI cuts within the T-DNA region, the released drop out fragment of $500 \mathrm{bp}$ confirmed the transgene integration into the soybean genome (Figure $4 \mathrm{a}$ ). The plasmid pBIN-bar showed a distinct hybridizing signal whereas the lane of control genomic DNA did not showed any hybridization. Southern analysis thus confirmed the stable integration of the transgene (bar) into the soybean genome. The identical integration pattern observed might be due to the fact that they have originated from the same transformation event. To further determine whether the transgenes were in the germinal tissue or whether the transgenic plants were chimeric, we sowed the selfed seeds from few of the $\mathrm{T}_{0}$ plants and assayed the progeny $\left(T_{1}\right)$ for bar expression. PCR analysis (Figure 5) revealed an analysis ratio which was close to the expected frequency for a single Mendelian dominant trait. Chisquare analysis further suggested the segregation ratio to be $3: 1$ (bar positive: bar negative) in $\mathrm{T}_{1}$ generation and a single functional locus of the transgene for all the transformants in the $\mathrm{T}_{1}$ generation (Table 3). Individual events showed the segregation pattern in a statistically significant manner $(p<0.05)$. Southern analysis of the progeny revealed a similar pattern of gene expression as in the parent plant suggesting at the closely linked nature of transgene in the genome (Figure $4 \mathrm{~b}$ ). It is also possible that we were unable to observe the negative segregants, due to a small sample size. On the other hand, the lack of bar gene inheritance in the $T_{1}$ generation of some events was likely due to either non germline transformation or chimerism in the $\mathrm{T}_{0}$ plant (Lowe et al. 1995; Parrott et al. 1989). Copy number pattern was not seen in the present study because $A$. tumefaciens most often provides a single integration pattern from an intact T-DNA copy in the plant genome; however it is not uncommon to find multiple T-DNA copies in the genome as well. Usually when this is the case, T-DNAs are in tandem or in a closely linked form (Tinland 1996). Additional restriction digestion experiments will however be necessary to determine the frequency of single versus multiple insertion events.

The results of Southern analysis and PCR screening were very much in accordance with glufosinate resistant analysis, thus confirming the presence and integration of transgene (bar) in transformants. We also screened 
Table 3. Segregation analysis of the progenies of $\mathrm{T}_{0}$ soybean plants for transgene $(+)$ : transgene $(-)$.

\begin{tabular}{lccccc}
\hline Transformed $\mathrm{T}_{0}$ lines & No. of $\mathrm{T}_{1}$ seeds tested & No. of $\mathrm{PCR}^{+\mathrm{ve}}$ plants & No. of PCR ${ }^{\text {-ve }}$ plants & Best fit & $p_{\text {-value }}{ }^{\mathrm{a}}$ \\
\hline BR11-3 & 45 & 35 & 10 & $3: 1$ & 0.7287 \\
BR17-6 & 26 & 18 & 08 & $3: 1$ & 0.3537 \\
BR21-2 & 62 & 45 & 17 & $3: 1$ & 0.5531 \\
BR26-8 & 9 & 08 & 01 & $3: 1$ & 0.3585 \\
BR31-11 & 16 & 12 & 04 & $3: 1$ & 1.0000 \\
BR9-13 & 18 & 15 & 03 & $3: 1$ & 0.5707 \\
\hline
\end{tabular}

${ }^{\mathrm{a}}$ Observed ratio is based on glufosinate resistant $\mathrm{PCR}^{\text {+ve }}$ plants.

(a)
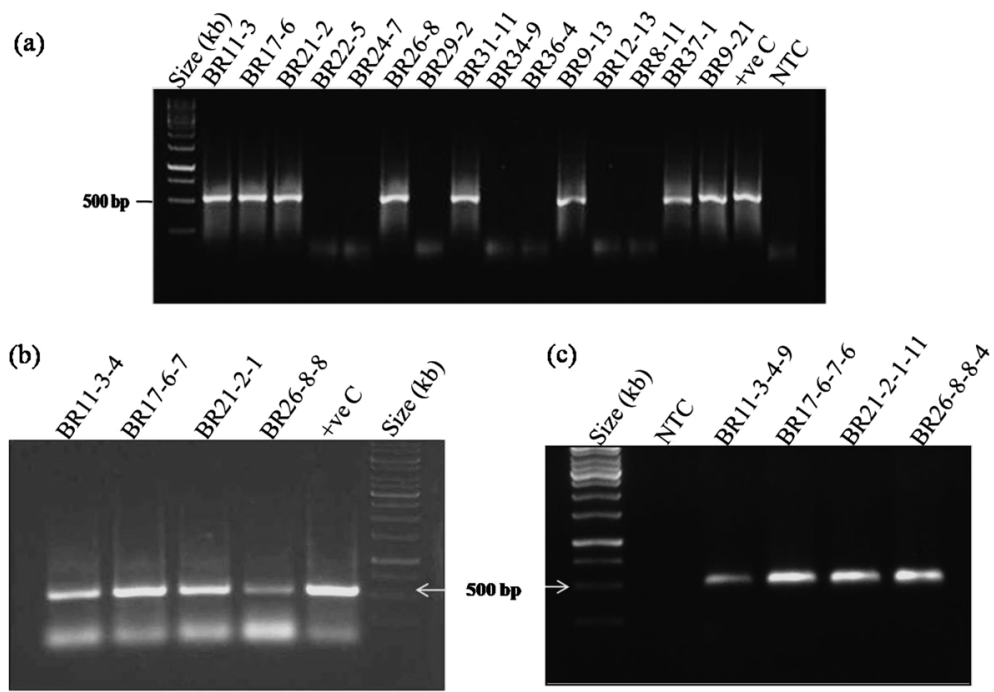

Figure 5. Molecular characterization of soybean plants transformed by Agrobacterium transformation using bar specific primers. PCR analysis on genomic DNA of transformed plants. lane NTC: non-transformed control plant; lane + ve C: positive control; lane size marker: $1 \mathrm{~kb}$ DNA ladder; (a) $\mathrm{T}_{0}$ transformed plants, lane BR11-3 to BR9-21: independent transformants, lane BR11-3, BR17-6, BR21-2, BR26-8, BR31-11, BR9-13, BR37-1, BR9-21 showing integration of bar gene in the plant genome, lane BR22-5, BR24-7, BR29-2, BR34-9, BR36-4, BR12-13 and BR8-11 showing absence of bar gene integration; (b) $\mathrm{T}_{1}$ transgenic plants, lane BR11-3-4 to BR26-8-8: independent transformants; (c) $\mathrm{T}_{2}$ transgenic plants, lane BR11-3-4-9 to BR268-8-4: independent transformants.

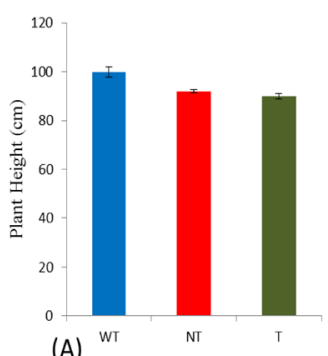

(A)

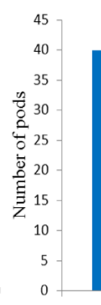

(B)

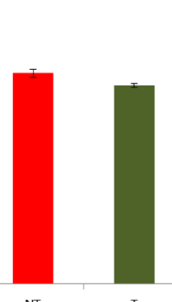

夏

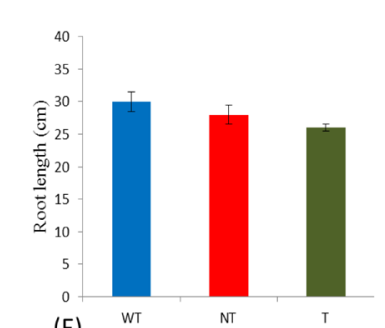

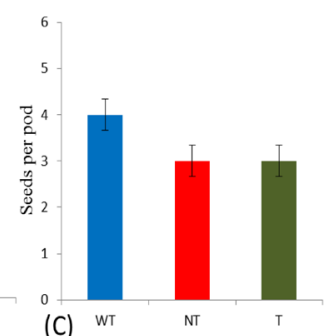

(C)
(D)

(E)

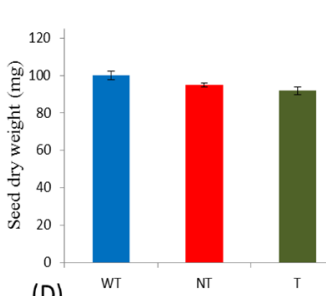

Figure 6. Agronomic traits analyzed in transgenic and non-transgenic soybean plants (A) Plant height (cm) (B) Number of pods (C) Seeds per pod (D) Seed dry weight $(\mathrm{mg})(\mathrm{E})$ Root length $(\mathrm{cm})$. No significant differences $(p<0.05)$ were observed between tissue culture generated non-transgenic and transgenic plants (BR11-3-4 to BR41-5-8). WT, wild type plant; NT, tissue culture generated non-transgenic plant; T- transgenic $\mathrm{T}_{1}$ plant. 
subsequent generations $\left(\mathrm{T}_{3}-\mathrm{T}_{4}\right)$ to circumvent the problem of chimeric plants due to the multicellular nature of the cotyledonary nodes using PCR (Hada A, Unpublished). The agronomic performance of the $T_{1}$ lines were compared with that of the non-transgenic plants (NT) as well as wild types (Figure 6) and different phenotypical and morphological personas were well thought-out and evaluated to consider the agronomic performance of transgenic plants. However, all the transgenic $\mathrm{T}_{1}$ and NT control plants showed significantly parallel morphologies at all the stages under study in terms of height, number of pods, number of seeds $\left(\mathrm{T}_{2}\right)$, seed dry weight, root length; and no significant $(p<0.05)$ variation was observed in the mentioned parameters. A comparatively high germ line transformation efficiency of $12.6 \%$, as revealed by the transformed glufosinate resistant events obtained in the present study shall make it possible to generate a large number of transgenic soybean plants in a relatively short period of time, which would further facilitate the testing of various transgenes for soybean improvement programmes.

\section{Conclusion}

A simple, stable and an efficient transformation protocol optimized in the present study for a consistent recovery of transgenic plants from the Indian soybean genotype JS-335 will greatly aid to meet the demands of the current high throughput soybean functional genomics and transgenic technology platforms.

\section{Conflict of interest}

The authors declare that they do not have any conflict of interest.

\section{Acknowledgements}

We are grateful to Dr. Anita Rani, Directorate of Soybean Research (DOSR), Indore, Madhya Pradesh, India for providing the seed samples. This work was supported financially by ICAR under National Funds for Basic Strategic and Frontier Application Research in Agriculture (NFBSFARA) programme.

\section{References}

Akama K, Puchta H, Hohn B (1995) Efficient Agrobacteriummediated transformation of Arobidopsis thaliana using the bar gene as selectable marker. Plant Cell Rep 14: 450-454

Anne F, Elizabeth DE (1996) An examination of factors affecting the efficiency of Agrobacterium-mediated transformation of tomato. Plant Cell Rep 16: 235-240

Bowen BA (1993) Markers for gene transfer. In: Kung S, Wu R (eds) Transgenic Plants: Engineering and Utilization, Vol. 1. Academic Press, San Diego, pp 89-123

Cabrera-Ponce JL, Vegas-Garcia A, Herrera-Estella L (1995) Herbicide resistant transgenic papaya plants produced by efficient particle bombardment transformation method. Plant Cell Rep 15: 1-7
Chen WP (2002) Agrobacterium-mediated transformation of American ginseng with a rice chitinase gene. Plant Cell Rep 20: 1039-1045

Clemente TE, LaVallee BJ, Howe AR, Conner-Ward D, Rozman RJ, Hunter PE, Broyles DL, Kasten DS, Hinchee MA (2000) Progeny analysis of glyphosate selected transgenic soybean derived from Agrobacterium-mediated transformation. Crop Sci 40: 797-803

D'Hallunm K, Botterman J, Degreef W (1990) Engineering of herbicide resistant alfalfa and evolution under field condition. Crop Sci 30: 866-871

Dennehey BK, Peterson WL, Ford-Santino C, Pajeau M, Armstrong CL (1994) Comparison of selective agents for use with the selectable marker gene bar in maize transformation. Plant Cell Tiss Org Cult 36: 1-7

Di R, Purcell V, Collins GB, Ghabrial SA (1996) Production of transgenic soybean lines expressing the bean pod mottle virus coat protein precursor gene. Plant Cell Rep 15: 746-750

Doyle JJ, Doyle JL (1987) A rapid DNA isolation procedure for small quantities of fresh leaf tissue. Phytochem Bull 19: 11-15

Feinberg AP, Vogelstein B (1983) A technique for radiolabelling DNA restriction endonuclease fragments to high specific activity. Anal Biochem 132: 6-13

Finer JJ, Mc Mullen MD (1991) Transformation of soybean via particle bombardment of embryogenic suspension culture tissue. In Vitro Cell Dev Biol Plant 27: 175-182

Finer JJ, Vain P, Jones MW, Mc Mullen MD (1992) Development of the particle inflow gun for DNA delivery to plant cells. Plant Cell Rep 11: 323-328

Gamborg OL, Miller RA, Ojima K (1968) Nutrient requirements of suspension cultures of soybean root cells. Exp Cell Res 50: 151-158

Hadi MZ, Mc Mullen MD, Finer JJ (1996) Transformation of 12 different plasmids into soybean via particle bombardment. Plant Cell Rep 15: 500-505

Hansen G, Wright Martha S (1999) Recent advances in the transformation of plants. Trends Plant Sci 4: 226-231

Hazel CB, Klein TM, Anis M, Wilde HD, Parrott WA (1998) Growth characteristics and transformability of soybean embryogenic cultures. Plant Cell Rep 17: 765-772

Hinchee MA, Connor-Ward DV, Newell CA, Mc Donnell RE, Sato SJ, Gasser CS, Fischhoff DA, Re DB, Fraley RT, Horsch RB (1988) Production of transgenic soybean plants using Agrobacteriummediated DNA transfer. Nat Biotechnol 6: 915-922

Kuta DD, Tripathi L (2005) Agrobacterium-induced hypersensitive necrotic reaction in plant cells: A resistance response against Agrobacterium-mediated DNA transfer. Afr J Biotechnol 4: 752-757

Liu HK, Yang C, Wei ZM (2004) Efficient Agrobacterium tumefaciens-mediated transformation of soybeans using an embryonic tip regeneration system. Planta 219: 1042-1049

Lowe K, Bowen B, Hoerster G, Ross M, Bond D, Pierce D, GordonKamm B (1995) Germline transformation of maize following manipulation of chimeric shoot meristems. Nat Biotechnol 13: $677-682$

Manickavasagam M, Ganapathi A, Anbazhagan VR, Sudhakar B, Selvaraj N, Vasudevan A, Kasthurirengan S (2004) Agrobacterium-mediated genetic transformation and development of herbicide-resistant sugarcane (Saccharum species hybrids) using axillary buds. Plant Cell Rep 23: 134-143

Murakami T, Anzai H, Imai S, Satoh A, Nagaoka K, Thompson CJ (1986) The bialaphos biosynthetic genes of Streptomyces hygroscopicus: Molecular cloning and characterization of the 
gene cluster. Mol Gen Genet 205: 42-50

Murashige T, Skoog F (1962) A revised medium for rapid growth and bioassays with tobacco tissue cultures. Physiol Plant 15: 473-479

Olhoft PM, Flagel LE, Donovan CM, Somers DA (2003) Efficient soybean transformation using hygromycin B selection in the cotyledonary-node method. Planta 216: 723-735

Olhoft PM, Lin K, Galbraith J, Nielsen NC, Somers DA (2001) The role of thiol compounds in increasing Agrobacterium-mediated transformation of soybean cotyledonary-node cells. Plant Cell Rep 20: 731-737

Parrott WA, All JN, Adang MJ, Bailey MA, Boerma HR, Stewart CN Jr (1994) Recovery and evaluation of soybean plants transgenic for a Bacillus thuringiensis var. kurstaki insecticidal gene. In Vitro Cell Dev Biol Plant 30: 144-149

Parrott WA, Hoffman LM, Hildebrand DF, Williams EG, Collins GB (1989) Recovery of primary transformants of soybean. Plant Cell Rep 7: 615-617

Paz MM, Shou H, Guo Z, Zhang Z, Banerjee AK, Wang K (2004) Assessment of conditions affecting Agrobacterium-mediated soybean transformation using the cotyledonary node explant. Euphytica 136: 167-179

Pigeaire A, Abernethy D, Smith PM, Simpson K, Fletcher N, Lu C-Y, Atkins CA, Cornish E (1997) Transformation of a grain legume (Lupinus angustrifolius L.) via Agrobacterium tumefaciens-mediated gene transfer to shoot apics. Mol Breed 3: 341-349

Sambrook J, Fritsch EF, Maniatis T (1989) A Laboratory Manual. Cold Spring Harbor, New York

Santarem ER, Finer JJ (1999) Transformation of soybean [Glycine $\max ($ L.) Merrill] using proliferative embryogenic tissue maintained on semisolid medium. In Vitro Cell Dev Biol Plant 35: 451-455

Schroeder HE, Schotz AH, Wardley-Richardson T, Spencer D, Higgins TJV (1993) Transformation and regeneration of two cultivars of pea (Pisum sativum L.). Plant Physiol 101: 751-757

Shelp BJ, Swanton CJ, Hall JC (1992) Glufosinate (Phosphinothricin) mobility in young soybean shoots. J Plant Physiol 139: 626-628

Somers DA, Samac DA, Olhoft PM (2003) Recent advances in legume transformation. Plant Physiol 131: 892-899

Stewart CN Jr, Adang MJ, All JN, Boerma HR, Cardineau G, Tucker D, Parrott WA (1996) Genetic transformation, recovery, and characterization of fertile soybean transgenic for a synthetic Bacillus thuringiensis cryIAc gene. Plant Physiol 112: 121-129

Sundar IK, Sakthivel N (2008) Advances in selectable marker genes for plant transformation. J Plant Physiol 165: 1698-1716

Thompson CJ, Movva NR, Tichard R, Crameri R, Davies JE, Lauwereys M (1987) Characterization of the herbicide-resistance gene bar from Streptomyces hygroscopicus. EMBO J 6: 2519-2523

Tinland B (1996) The integration of T-DNA into plant genomes. Trends Plant Sci 1: 178-184

Tran Thi Cuc Hoa (2008) Efficiency of developing transgenic soybean from the varieties MTÐ 176, HL 202, Maverick and Williams- 82 by cotyledonary-node method using Agrobacterium tumefaciens-mediated transformation. J Agric Rural Dev 1: 14-19

Trick HN, Dinkins RD, Santarn ER, Di R, Samoylov V, Meurer CA, Walker DR, Parrott WA, Finer JJ, Collins GB (1997) Recent advances in soybean transformation. Plant Tissue Cult Biotechnol 3: 9-26

Vasudevan A, Selvaraj N, Ganapathi A, Choi CW (2007) Agrobacterium-mediated genetic transformation in cucumber (Cucumis sativus L.). Am J Biochem Biotechnol 3: 24-32

Wang K, Frame B, Marcell L (2003) Genetic transformation of maize. In: Jaiwal PK, Singh RP (eds) Plant Engineering, Vol. 2, Improvement of Food Crops. Sci Tech Publishing LLC, USA, pp 175-217

Wehrmann A, Vliet AV, Opsomer C, Botterman J, Schulz A (1996) The similarities of bar and pat gene products make them equally applicable for plant engineers. Nat Biotechnol 14: 1274-1278

Widholm JM (1995) Leguminous plants. In: Wang K, HerreraEstrella A, Van Montagu M (eds) Transformation of Plants and Soil Microorganisms. Cambridge University Press, Cambridge, pp 101-124

Zeng P, Vadnais DA, Zhang Z, Polacco JC (2004) Refined glufosinate selection in Agrobacterium-mediated transformation of soybean [Glycine max (L.) Merrill]. Plant Cell Rep 22: 478-482

Zhang Z, Xing A, Staswick P, Clemente TE (1999) The use of glufosinate as a selective agent in Agrobacterium-mediated transformation of soybean. Plant Cell Tiss Org Cult 56: 37-46 